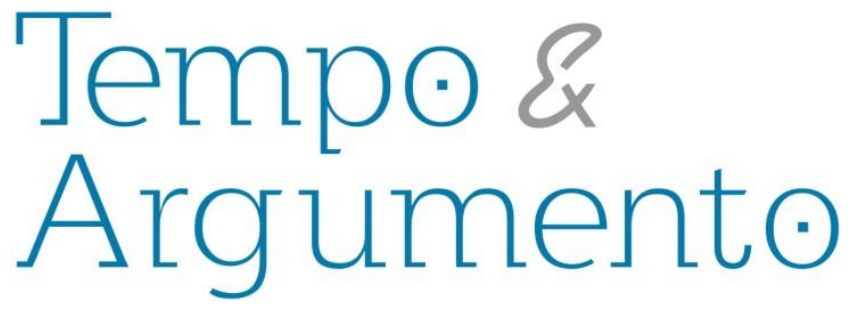

\title{
O futuro da leitura? Recordações e Pensamentos por uma Abordagem Genealógica
}

Tradução do texto "The Future of Reading? Memories and Thoughts toward a Genealogical Approach", de Hans Ulrich Gumbrecht, publicado na revista boundary 2 an international jornal of literature and culture, volume 41, número 2, 2014, p. 99-111.

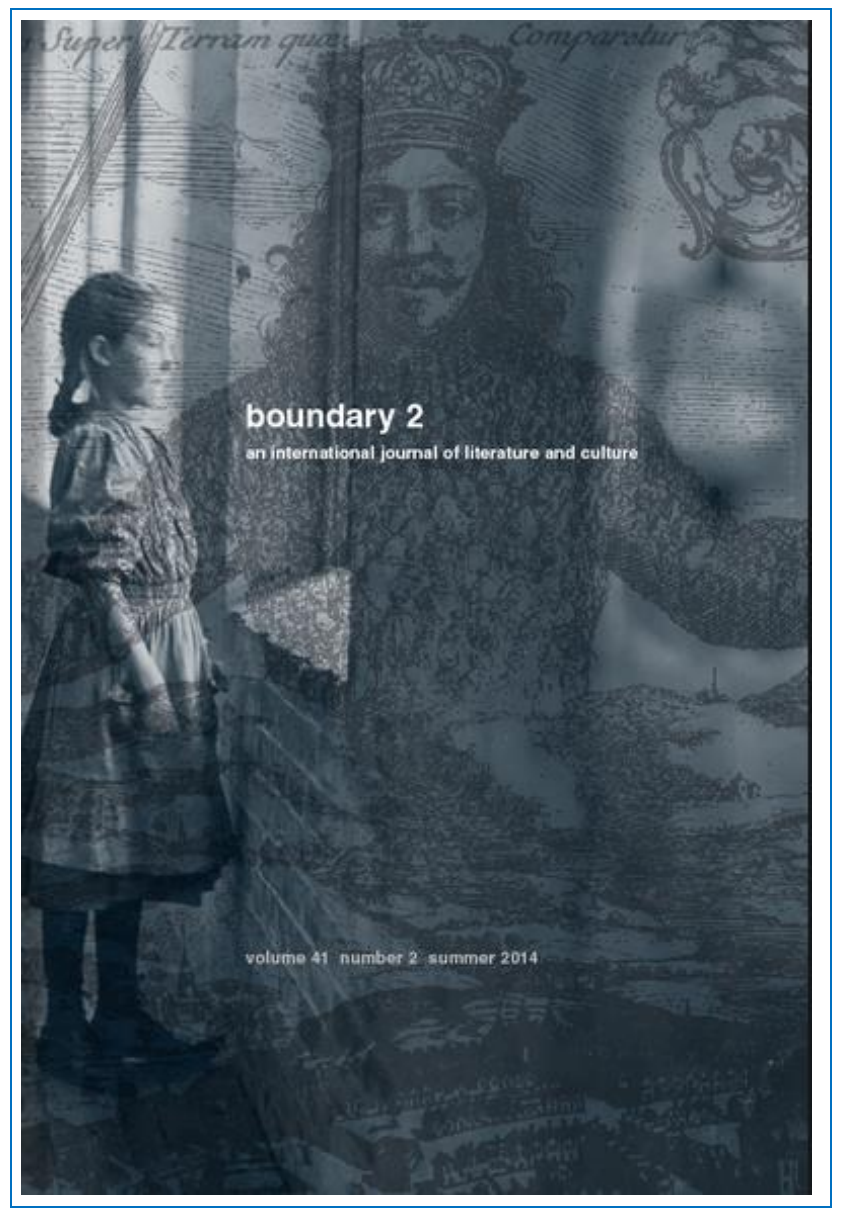

\section{Autor da Obra}

\section{Hans Ulrich Gumbrecht}

Especialista em teoria da literatura, literatura comparada e filosofia. É professor emérito do Departamento de Literatura Comparada da Stanford University.

\section{Tradutor}

\section{Nelson Shuchmacher Endebo}

Doutorando no programa de Literatura Comparada da Stanford University (EUA). nse@stanford.edu

Revisor

\section{Marcelo de Mello Rangel}

Doutorado em História Social da Cultura pela Pontifícia Universidade Católica do Rio de Janeiro (PUC-Rio). Professor da Universidade Federal de Ouro Preto (UFOP). Mariana - MG - BRASIL mmellorangel@yahoo.com.br

\section{Para citar esta tradução:}

GUMBRECHT, Hans Ulrich. O futuro da leitura? Recordações e Pensamentos por uma Abordagem Genealógica.Tempo e Argumento, Florianópolis, v. 10, n. 24, p. 628 - 643. abr./jun. 2018. Tradução de: Hans Ulrich Gumbrecht; The Future of Reading? Memories and Thoughts toward a Genealogical Approach. boundary 21 May 2014; 41 (2): 99-111. 
As questões e o argumento desenvolvidos nesse texto remontam à minha contribuição para a série de conferências "How I Think About Literature", em 17 de Outubro de 2011, na Universidade de Stanford. Agradeço à Professora Gabriella Safran, catedrática da Divisão de Literaturas, Culturas e Línguas, pela iniciativa e pelo convite.

(1)

Na última primavera eu passei algumas semanas intelectualmente estimulantes junto a um grupo de dezoito alunos de graduação no campus internacional de Stanford em Santiago do Chile, sob o céu predominantemente escuro e constelado que marca a passagem do outono e o advento do inverno no hemisfério sul. A maioria desses estudantes cursava o terceiro ano, nenhum deles na área de Humanas. Seus interesses acadêmicos e áreas de concentração variavam de Relações Internacionais até Ciências Políticas; de Geologia e Arquitetura até Física Teórica; de Geociências até Biologia Humana. Antes de qualquer outra coisa, eu os reconheci capazes de boas avaliações sempre que confrontados com problemas complexos, tanto dentro como fora de suas áreas de estudo, notavelmente bem informados e sempre sedentos por aprender mais e, com isso, expandir seus horizontes de experiência. Graças às nossas discussões, consegui progredir substancialmente no meu programa de trabalho e estudo para os dois cursos que ministrei, um sobre “Tipologia Histórica dos Intelectuais na América Latina”, o outro sobre "História Cultural do Futebol na América do Sul”. 
A diferença considerável de idade que nos separava, quarenta anos, em momento nenhum trouxe qualquer obstáculo para as nossas conversas, no entanto, nunca havia me sentido tão perplexo diante da maneira como a nova geração pratica a leitura. A maioria dos meus alunos mostrou-se incrivelmente rápida e ágil tanto na hora de identificar os tópicos, usualmente complicados, quanto os problemas-chave, nos textos em inglês e espanhol que discutíamos; ao mesmo tempo, eles pareciam carecer de atenção primária e sensibilidade para as dimensões retórica e estilística e, às vezes, também poética dos textos. Eu não me refiro, evidentemente, a uma falta de instrumentos específicos de análise textual, os quais esperaríamos de um estudante de Letras. Entre a minha técnica de leitura e a deles o que notei não foi uma disparidade de nuance ou grau, mas sim uma diferença drástica beirando o plano ontológico. Tive a impressão de que meus alunos passavam por cima das camadas formais dos textos que liam, como se tentassem acessar as dimensões semântica e argumentativa com um imediatismo assombroso. A despeito disso, me surpreendeu a facilidade com que pude fazê-los se interessar por estruturas sintáticas, tropos de discurso, configurações de metáforas - e sempre que isso acontecia, eu percebia um contentamento genuíno, qual a alegria de descobrir o Mediterrâneo. Em alguns casos, esse interesse praticamente alcançava o patamar de um leve vício.

Em nenhum momento me senti tentado a interpretar minhas observações no espírito da crítica cultural clássica, isto é, como sintoma de um declínio ou de um investimento intelectual ou existencial insuficiente. Afinal de contas, esses alunos passavam o dia inteiro lendo, provavelmente mais do que qualquer outra geração que eu tenha visto: lendo e-books, nas telas de seus computadores e iPhones, e às vezes até mesmo livros em papel ou apostilas. Eles liam enquanto escreviam; liam com atenção exclusiva na leitura; liam enquanto escutavam música ou batiam papo com os amigos. Sem dúvida, foi essa sobrecarga de uma prática ininterrupta de leitura que os tornara capazes de processar em “informação” quantidades inauditas de texto. Quando Ihes perguntei, ainda no início dos cursos, se preferiam focar em apenas uma parte do material incluído nas volumosas apostilas, eles unanimemente optaram por não omitir nenhum texto, desafiando mais a minha capacidade de leitura do que a sua própria. Pela 
primeira vez em minha vida, porém, essa decisão também me fez questionar se o uso indiscriminado da mesma palavra para descrever os hábitos de leitura daqueles alunos e os da minha geração não era enganoso e, portanto, problemático.

É claro que o que estou dizendo nada tem de inédito. Aquilo que foi uma observação intelectualmente elegante há quinze ou vinte anos tornou-se um fato bruto capaz de influenciar o nosso cotidiano: o uso permanente das mídias eletrônicas, em sua sempre crescente diferenciação técnica e poder prático, produziu e continua a impelir a transformação de hábitos mentais que no fim das contas poderá, muito provavelmente, ser mais profunda do que a alteração que, retrospectivamente, imaginamos ter ocorrido na transição entre a era do manuscrito e a era da prensa móvel. Entretanto, o que se menciona com muito menos freqüência é que, para aqueles entre nós que ganham a vida aperfeiçoando a habilidade de leitura das gerações futuras, isso tudo significa literalmente que já não sabemos mais, e não sabemos ainda, o que constitui exatamente a "leitura" para aqueles que ensinamos a ler. Para piorar, carecemos, nos estudos literários e na linguística, até mesmo de métodos para iniciarmos investigações promissoras acerca do futuro da leitura.

As teorias da recepção, consideradas nas várias posições e afiliações acadêmicas que marcaram seu ápice nos anos 70, pouco nos ajudam, uma vez que, queiram elas salientem as várias interpretações dadas a textos por grupos de leitores historicamente diferentes, queiram elas se concentrem nos tipos de discussão que textos literários podem promover na sala de aula, elas sempre pressupõem um tipo homogêneo de leitura focada tanto na forma, quanto no conteúdo; leitura que nos parecia "natural” há uma ou duas décadas - e que visivelmente já não corresponde à de nossos alunos. O trabalho de historiadores como Roger Chartier ${ }^{1}$, que busca reconstruir minuciosamente técnicas de leitura anteriores, atende melhor aos requisitos de nossa tarefa aqui, pois o escopo adotado, marcadamente mais amplo, relaciona à produção de sentido gestos de

\footnotetext{
${ }^{1}$ Ver, por exemplo, Roger Chartier: The Order of Books. Readers, Authors, and Libraries in Europe between the Fourteenth and Eighteenth Centuries. Stanford, 1994.
} 
investimento corporal e detalhes sobre a materialidade de diversos suportes de textos. Contudo, também essa abordagem precisaria sofrer uma transformação a fim de se adequar às necessidades empíricas da investigação sobre o passado e o futuro da leitura.

Eu certamente não me encontro na posição de oferecer o aparato teórico, metodológico e prático que essa investigação exige; tampouco posso anunciar seus primeiros insights e resultados. O que creio poder contribuir diz respeito a uma outra dimensão do problema. A revolução eletrônica impactou a cultura da leitura sob condições institucionais singulares e dentro de um contexto histórico com premissas epistemológicas e mentais específicas. Tais condições e premissas por sua vez ajudaram a modular o efeito das novas tecnologias sobre a leitura, e por essa razão integram a genealogia da nova cultura da leitura. Dado que elas influenciaram também a minha própria socialização profissional, grande parte do que buscarei descrever a seguir se baseia em recordações pessoais. Em última análise, espero poder utilizar essas reminiscências como base para aprofundar reflexões sobre os contextos de emergência da nova cultura da leitura, reflexões que talvez nos permitam fundamentar algumas hipóteses sobre o seu futuro.

O meu primeiro contato acadêmico imediato com as Humanas nos Estados Unidos remonta às duas experiências que tive como professor visitante no Departamento de Francês e no Departamento de Literatura Comparada na Universidade da Califórnia, Berkeley, em 1980 e 1983, que foram decisivas para o que, à época, ainda era o meu futuro profissional, sobretudo porque as duas temporadas em Berkeley me obrigaram a reconhecer as premissas básicas do meu próprio trabalho, e a vê-las em perspectiva. Ainda lembro do meu estarrecimento, na discussão em sequência à conferência que proferi $^{2}$ para professores e doutorandos em meus departamentos, ao ouvir um colega dizer (ainda hoje consigo ver sua face, ouvir sua entonação, e sentir o desconforto de meu constrangimento): “Nós esperávamos uma leitura especializada [expert], mas o que

\footnotetext{
2 "The Ever Rising Bourgeoisie in Histories of Literature".
} 
você nos ofereceu foi uma narrativa ingênua". Na época, a desconstrução (enquanto posição intelectual) era algo novo demais para que eu pudesse compreender com clareza que a expressão "narrativa ingênua" implicava uma reivindicação de identificação com o estilo discursivo de Jacques Derrida. Porém, certamente senti o quão fundamental - e devastadora - a crítica à minha técnica de leitura pretendeu ser. Eu aprendi ali que, nas universidades americanas e na sociedade americana em geral, a "leitura", enquanto prática cultural, ou melhor ainda, a "leitura como tal”, ostentava uma aura com a qual eu simplesmente não estava acostumado. Sete anos depois, quando dei a minha aula inaugural ("O Corpo como Objeto de Estudos Literários") como professor de literatura em Stanford, pude observar momentos similares, ainda que não tão ásperos - e assim confirmei minhas impressões de uma diferença cultural profunda e frequentemente subestimada.

Hoje eu fico pasmo sobretudo com os tópicos e títulos que me interessavam há 30 anos, e foram as reações àquelas primeiras aulas que chamaram minha atenção pela primeira vez para os graves contrastes existentes naquilo que hoje parece ter sido o hábito de leitura monocromático dos scholars na era do livro; contrastes visíveis sobretudo entre as modalidades de leitura anglo-americana e a alemã, mais “hermenêutica”. A singularíssima ressonância que a Desconstrução obteve nos departamentos de literatura nos EUA sem dúvida dependeu da afinidade entre seu enfoque de leitura meticulosamente "literal", e aquele da tradição do New Criticism, legado acadêmico das décadas de 1920 e 1930. O New Criticism, por sua vez, fundamentava-se supostamente na longeva tradição protestante de leitura da Bíblia.

Essa associação convencional da aura da leitura segundo o New Criticism com a da leitura protestante foi, todavia, problemática desde o início - pela simples razão de que há muito a mesmíssima genealogia já havia sido reivindicada por uma modalidade de leitura intrinsicamente distinta: a da Hermenêutica alemã. Se é possível que o New Criticism e a Hermenêutica tenham se originado a partir do enfoque programático que a Reforma destinou ao texto bíblico (em seu sentido "literal" e por meio das traduções para os vários vernáculos), mais tarde os dois se distinguiriam em posições quase opostas dentro da tradição de leitura de livros. A Hermenêutica busca realizar-se na fusão 
existencial (Verschmelzung, como quis Hans-Georg Gadamer) entre o mundo constituído em um texto e os horizontes de experiência de seus leitores, ao passo que, para os New Critics, o texto permanece alheio às preocupações e aos sentimentos pessoais. Por um lado, uma análise à maneira dos New Critics enfatiza e elabora os contornos formais e semânticos de um texto como objeto e condição para múltiplas leituras (esta descrição, acredito, converge com o conceito de "leitura retórica" de Paul de Man)3; a Hermenêutica, por outro, busca integrar ao cerne da identidade do leitor interpretações ou atribuições de sentido (Gehalt, em alemão, que indica a convergência de forma e conteúdo) mutáveis e, também, individualizadas.

Esses contrastes e tensões entre diferentes legados de leitura, revelados gradualmente em um cenário acadêmico cada vez mais internacionalizado, foram apenas duas das transformações decisivas que os Estudos Literários sofreram durante as décadas de 1970 e $1980^{4}$. Aqueles anos testemunharam também uma frustração paulatina com as diversas propostas de um conceito de literatura válido tanto do ponto de vista metahistórico quanto transcultural, propostas que desempenharam papel capital para o surgimento da Teoria da Literatura como subdisciplina dos Estudos Literários no início do século $X X$, e que acompanharam e até mesmo deflagraram muitos de seus debates internos. O ensaio seminal de Michel Foucault, "O que é um Autor?"5, marcou essa mudança de eixo decisiva ao pleitear a historicização radical de todos os conceitos outrora considerados meta-históricos pelos Estudos Literários como a única postura epistemologicamente aceitável. Como os primeiros representantes da Teoria da Literatura, em particular os Formalistas Russos, haviam insistido que a legitimidade das disciplinas acadêmicas depende da possibilidade de as erigirmos sobre uma fundação

\footnotetext{
${ }^{3}$ A referência fundamental é - Paul de Man: Semiology and Rhetoric, in: Diacritics 3 (Outono, 1973), pp. 2733.

4 Sobre as observações subsequentes acerca dos Estudos Literários, ver Hans Ulrich Gumbrecht: The Nineteenth and Twentieth Century Tradition of (Academic) Literary Studies: Can it Set an Agenda for Today? Transnational Lecture Series / University of Manchester, n. 4. Manchester, 2009.

${ }^{5}$ A referência original é: Qu'est-ce qu'un auteur? In: Bulletin de la Société française de philosophie, 63 (1969), pp. 73-104.
} 
nocional meta-histórica, a nova insegurança circundando o conceito de "literatura" deflagrou (de modo muitas vezes barulhento) um movimento programático de transformação dos Estudos Literários em Estudos Culturais. Por volta de 1990, um grande número de estudiosos da literatura viu-se repentinamente qualificado para expandir dramaticamente o espectro de fenômenos que eles podiam ensinar e pesquisar, desde textos literários (que já não podiam mais servir de horizonte homogêneo de referência) até a música, o cinema, as artes plásticas; desde classe, gênero sexual e raça até qualquer coisa que pudesse ser chamada de "cultural" (que, dada a extensão semântica da expressão, não exclui praticamente nada).

Pode-se dizer que, por falta de alternativas mais convincentes, os paladinos dos Estudos Culturais seguiram aplicando técnicas de leitura hermenêuticas ou desconstrucionistas (New Critical) a uma gama de objetos de estudo vastamente amplificada, aceitando e até mesmo encorajando uma erosão progressiva do que se entendia por "leitura” até então. A competência para leituras literárias especificamente reivindicada pela hermenêutica e pelo New Criticism foi transferida para a "leitura" de fenômenos como sinfonias, pinturas, ou marcas de identidade sexual. Em muitos casos, os resultados desse movimento afobado de dominação acadêmica foram tão banais, tão aquém de suas pretensões de glória e dos padrões tradicionais de qualidade intelectual dos Estudos Literários, que eles infligiram um dano permanente ao prestígio público das Humanas.

Eu devo admitir, um tanto atônito, que o meu primeiro projeto de livro desenvolvido nos EUA teve como ponto de partida as premissas dos Estudos Culturais ${ }^{6}$. Nele, procurei descrever o perfil de um ano remoto (escolhi 1926), supondo que, a fim de captar sua identidade, qualquer artefato surgido naquele ano, ou que nele tenha encontrado ressonância particularmente forte, poderia me ser útil. Daí minha surpresa, após terminar a primeira versão do meu manuscrito no verão de 1995, ao perceber que, a despeito do ambiente institucional dominado pelos Estudos Culturais, a maioria dos textos que eu havia utilizado eram textos literários no sentido tradicional do adjetivo isto é, o sentido então contestado. Qual teria sido a razão - supostamente pré-consciente

\footnotetext{
${ }^{6}$ O produto final foi: In 1926. Living on the Edge of Time. Cambridge, MA, 1997.
} 
- das minhas escolhas? Atrás de uma resposta para essa pergunta, passei a me concentrar cada vez mais na "concretude" da literatura, isto é, em um predicado ao qual se referiram tantos teóricos da literatura no século XX, entre eles Georg Lukács na "Teoria do Romance"7, na tentativa (em última análise fracassada) de elaborar uma definição metahistórica e transculturalmente válida. Mas se predecessores como Lukács haviam apreciado a concretude de textos literários como modo de aperfeiçoar o potencial explicativo que estes lançavam sobre o passado, eu intuí que as individualidades concretas de personagens, objetos e situações (ficcionais) nos textos arrolados, ao invés de ajudarem a entender o ano 1926, simplesmente tornavam aquele ano mais presente, o invocavam, produziam, de modo geral, uma impressão mais intensa de imediatismo (em todo caso, em uma abordagem focada em um ano como momento sincrônico e não como sequência, será mesmo que havia lugar para o "entendimento", para a identificação de precedentes de fenômenos atuais, bem como as razões para seus desdobramentos?).

Meu livro In 1926: Living on the Edge of Time, foi publicado em 1997. Na década seguinte, a noção de "presença" crescia em importância quanto mais eu tentava moldar uma relação com o passado que não enfatizasse o "entendimento", e formular uma concepção de leitura de textos literários e não-literários que não fosse nem hermenêutica, nem desconstrucionista ${ }^{8}$ (importância compartilhada com muitos outros críticos literários que empregavam abordagens e terminologias teóricas diferentes das minhas) $)^{9}$. Acredito que dentro desse grupo um conceito mais geral de "literatura" tornou-se mais uma vez viável. Contudo, é provavelmente melhor que não tenha havido esforços programáticos para reabilitá-lo ou até mesmo redefini-lo como fundamentação epistemológica para os estudos literários - até mesmo porque o novo modo de leitura, mais orientado pela presença, embora principalmente associado a textos que chamaríamos espontaneamente "literários", não carrega em si o enfoque tradicional um

\footnotetext{
7 "Die Theorie des Romans. Ein geschichtsphilosophischer Versuch über die Formen der grossen Epik" foi escrito na Alemanha durante os anos de 1914/1915, e publicado em 1916.

8 O manifesto para essa posição foi: Production of Presence - What Meaning Cannot Convey. Stanford, 2004.

${ }^{9}$ Um sumário interessante dessas posições (e de diferentes reações a elas) está disponível em Sonja Fielitz (ed.): Praesenz interdisziplinaer. Kritik und Entfaltung einer Intuition. Heidelberg, 2012.
} 
tanto mais estreito naqueles textos. Em um recorte pessoal, ainda dentro do contexto maior da década passada, eu venho tentando desenvolver conceitos como Stimmung (isto é, "atmosfera”, “ânimo”, “clima”, em alemão) ${ }^{10}$ ou a noção complementária de latência, como ferramentas descritivas das variações históricas em práticas de leitura de textos literários, bem como seus efeitos ${ }^{11}$. Em um contexto educacional, esse tipo diferente de leitura, com todas as suas variações e nuances, já não valorizaria tanto a interpretação ou análise literária objetivando resgatar o potencial semântico e formal de textos (Gehalt) e sim a elaboração de gestos de dêixis. Em nossa situação atual, me parece mais apropriado, como prática pedagógica, atrair leitores potenciais até certos textos, e incentivar que estes sejam lidos em múltiplos níveis, do que adotar as posições inevitavelmente autoritárias de dizer o que textos devem (ou hão de) "realmente" significar, e como foram feitos.

O estado dos Estudos Literários como instituição acadêmica ao final do século XX é apenas uma camada complexa em relação a condições genealógicas que foram fundamentais à ação das mídias eletrônicas sobre os hábitos de leitura da nossa e das novas gerações. Junto com o interesse renovado dos estudiosos pela "presença" (e fenômenos relacionados), essa situação integra uma mudança muito mais profunda na condição humana, uma mudança que ocorreu, por assim dizer, "na surdina", uma mudança que diz respeito, acima de tudo, às formas institucionais de nossas relações com o passado, o futuro e o presente. Para falar dessas "construções sociais do tempo" eu utilizo a palavra "cronótopo", modificando-lhe ligeiramente o sentido dado por Mikhail Bakhtin 12. Eu creio que o cronótopo "historicista”, que a partir de 1800 alcançara tal êxito a ponto de ser confundido com o tempo por si e em si mesmo (isto é, o cronótopo que

\footnotetext{
${ }^{10}$ Atmosphere, Mood, Stimmung. On a Hidden Potential of Literature. Stanford, 2012 (German original Stimmungen lesen, München, 2011).

${ }^{11}$ Ver Hans Ulrich Gumbrecht / Florian Klinger (eds.): Latenz. Blinde Passagiere in den Geisteswissenschaften. Göttingen, 2012.

${ }^{12}$ Mikhail Bakhtin: Forms of Time and the Chronotope in the Novel. In: The Dialogic Imagination. Four Essays. Austin, 1981, pp. 84-258.
} 
possibilitou a filosofia da história de Hegel e o evolucionismo de Darwin), tenha sido contestado, e quase substituído, pela emergência de um outro cronótopo nos últimos cinquenta anos, e que essa nova situação de coexistência e tensão entre os dois cronótopos desempenhou uma influência irreversível sobre a maneira como nós e as novas gerações lêem hoje. ${ }^{13}$

Visando à brevidade, e apoiando-me, sobretudo, no trabalho histórico de Reinhart Koselleck ${ }^{14}$, almejo descrever o cronótopo historicista decompondo-o em cinco aspectos. Primeiramente, trata-se do cronótopo no qual o presente sempre deixa o passado para trás, enfraquecendo seu valor orientador e forçando-nos a encarar o passado a fim de dispormos de um futuro aberto, moldável; segundo, o cronótopo historicista trata o futuro como um horizonte aberto de possibilidades entre as quais decidimos e escolhemos; em terceiro lugar, entre o passado que deixamos para trás e um futuro selecionável, o presente se torna um "momento de transição imperceptivelmente breve", como escreveu Charles Baudelaire em seu "Pintor da Vida Moderna", de 1858; quarto, para a construção historicista do tempo, esse presente é o habitat e a condição para a autocompreensão humana como Sujeito e Agente, isto é, como sinônimo do potencial funcional da consciência (no sentido do "Penso, logo existo" de Descartes, e incluindo o agir, no sentido de Handlung) - é neste presente que, ajustados pela experiência do passado, nós escolhemos entre as possibilidades de futuro, o que significa que nós agimos sempre e tão somente no presente; por fim, nesse cronótopo historicista o tempo aparenta ser um agente de mudança irresistível, o que implica dizer que fenômeno algum é capaz de escapar à transformação no tempo e pelo tempo, em nada importando quão ligeiro ou vagaroso seja o ritmo da transformação específica. Ao longo dos últimos anos, eu me convenci de que tais descrições cronotópicas podem ser utilizadas como ferramentas para um novo tipo de análise histórica totalizante. Totalizante, pois sua complexidade nos permite arregimentar em um contexto uma pletora de fenômenos contemporâneos. Aqui, contudo, diferentemente das ferramentas

\footnotetext{
13 Para uma descrição "histórica" e argumentos filosóficos no que diz respeito à afirmação de que houve "uma mudança na condição humana”, ver Hans Ulrich Gumbrecht: After 1945 - Latency as Origin of the Present. Stanford, 2013. E Unsere breite Gegenwart, Berlin, 2011 (Tradução para o inglês em preparação, Columbia University Press, 2014) se concentra no que eu me refiro como sendo o "novo cronótopo".

${ }^{14}$ Sobretudo em: Future's Past. On the Semantics of Historical Time. New York, 1985.
} 
de totalização tradicionais, e devido à própria complexidade dos cronótopos, não há um conceito dominante capaz de subsumir em si esses fenômenos.

Sem sombra de dúvida, a leitura Hermenêutica foi - ainda é - produto do cronótopo historicista, pois a "fusão" da situação existencial do leitor com outras, proporcionada pelos textos, é uma instância do complexo ato historicista de escolher e moldar um futuro, no presente, com base em experiências passadas adaptadas ao presente. A leitura hermenêutica ocorre, portanto, sempre dentro da tensão específica entre as três dimensões temporais tal como constituída pelo cronótopo historicista. Todavia, a auto-referência cartesiana que esse cronótopo produz também é a condiçãochave para a leitura do New Criticism. Ora, se auto-referência como consciência é condição necessária para a "fusão" hermenêutica com o passado, ela também funciona como pré-condição para a análise textual e para o progressivo encerramento recíproco entre o leitor retórico (novamente no sentido de Paul de Man) e o texto enquanto objeto. Nessa operação a relação entre passado, futuro e presente ainda é "consciência histórica", mas a dinâmica produzida pela tensão temporal se dá aparentemente em um nível inferior de intensidade.

Em contraste, no novo cronótopo, aquele que eu acredito reger o cotidiano na cultura global contemporânea, e que associo à comunicação eletrônica (sem, no entanto, identificá-la como a sua "origem" ou "causa”), o futuro, ao invés de ser um horizonte aberto de possibilidades, é ocupado por ameaças que parecem se dirigir ao presente, isto é, por visões de catástrofes ecológicas, demográficas ou econômicas, cujos adventos podem ser protelados, mas, em última análise, jamais evitados (não julgo aqui o realismo de tais visões). Em segundo lugar, o passado do novo cronótopo, ao invés de ser deixado para trás pelo presente, o inunda - ou seja, nada mais pode ser esquecido ou substituído (a capacidade praticamente infinita de memória da comunicação eletrônica ilustra essa mudança, e talvez seja uma de suas condições de possibilidade). Terceiro, entre o futuro obstruído e esse passado que jamais se esvanece, o novo presente se torna um presente de simultaneidades a dilatar-se perpetuamente, um presente expansivo no qual o vetor dinâmico do tempo historicista desaparece. Se, em quarto lugar, se associava o presente estreito do cronótopo historicista à auto-referência cartesiana, isto é, a uma concepção 
de ser humano exclusivamente baseada na consciência, podemos supor que a estrutura drasticamente diferente do presente expansivo proporciona novas variedades de autoreferência (o que talvez explique, por exemplo, porque as últimas décadas têm se obcecado tanto com esforços filosóficos e práticos de "restituir" à vida humana "o corpo" e tantas formas de sensibilidade corporais). Por fim, nem é preciso dizer que, no novo cronótopo, o tempo já não parece mais um agente necessário de mudança. Em outras palavras: tornaram-se novamente aceitáveis situações de continuidade, novas formas de "conservadorismo" (pensemos nos movimentos "verdes") e até mesmo pensamentos sobre as condições permanentes da vida humana.

Quais seriam, para o futuro da leitura, as possíveis consequências da nossa nova situação cronotópica, dessa alteração de estado da condição humana? Neste momento, considero a promessa intelectual dessa pergunta mais interessante do que as respostas preliminares e experimentais que eu seria capaz de formular sem desconforto. Sendo assim, ao invés de insistir no valor analítico ou mesmo factual das minhas conclusões, espero que elas sejam recebidas como indicações do quão longe a abordagem genealógica poderá nos levar, caso a sigamos.

Começo com a seguinte premissa. Se a "lógica" inerente do novo cronótopo inclui a tese de que nenhum fenômeno ou instituição pode ser deixado para trás, esse cronótopo não substituirá gradualmente o anterior, mas ambos coexistirão em uma relação de competição ou complementaridade. Vista desse ângulo, a situação de meus seminários em Santiago, com a co-presença de dois estilos de leitura marcadamente distintos, pode muito bem ter sido uma antecipação do nosso futuro. O estilo primário de leitura de meus alunos, que cresceram e foram educados em um ambiente saturado pela comunicação eletrônica, toma por base a consciência e a razão de forma realmente hiperbólica, o que explica seu desempenho notável na hora de processar grandes quantidades de textos naquilo que eles gostam de chamar de "informação". Dentro de nosso presente expansivo, contudo, esse papel dominado pela consciência e pela 
autorreferência, que os computadores somente fortalecem e acentuam, é provavelmente menos exclusivo e mandatório para os estilos de leitura hermenêutica e New Critical do que costumava ser outrora sob condições historicistas. Por essas razões, suponho que meus alunos, tão experientes com aparelhos eletrônicos, se impressionavam de imediato sempre que eu lhes chamava atenção para os aspectos formais dos textos que líamos juntos, e se sentiam facilmente atraídos por modos de leitura que visavam tornar presentes situações passadas e culturas estrangeiras com suas texturas específicas de Stimmung e sensibilidade. Sob as condições do presente expansivo, a comunicação não é tanto quanto imaginamos uma estrada de mão única, que nos leva para longe do concreto e do sensível.

Por outro lado, há claramente uma afinidade entre um presente de simultaneidades perpetuamente expansivo, um presente no qual literalmente tudo está ao nosso alcance, e uma forma de existência que se realiza nas transições flutuantes entre modos distintos de comunicação eletrônica. Essa convergência entre o presente expansivo e a onipresença dos dispositivos eletrônicos torna permanente a leitura, e faz o ato de ler perder contornos, foco e direção. Há apenas vinte anos atrás, leituras ostensivamente concentradas em um aspecto particular do texto [reading for], p. ex. no enredo [reading for the plot], eram popularmente caracterizadas como modos distintos de leitura. Distinções como essas, baseadas em núcleos de atenção, hoje já não parecem apropriadas para descrever a cultura de leitura das novas gerações.

Para finalizar, eu gostaria de mencionar uma dimensão outrora central para as diferentes culturas de leitura dentro do cronótopo historicista: o status daqueles textos que costumávamos chamar de "clássicos". "Clássicos" eram chamados aqueles textos capazes de manter um apelo de frescor e imediatismo frente à erosão dos tempos; o que eles realizavam era a paradoxal exceção dentro do cronótopo no qual o presente continuamente abandona o passado. Em um presente de simultaneidades expansivo, em contraste, e aliado a uma tecnologia que torna impossível o esquecimento, a presença e o imediatismo dos textos do passado perderam sua excepcionalidade e empolgação características. Enquanto a "aura" dos clássicos assim se deteriorar, sua função como instituição se verte em uma questão de escolha pessoal - a qual nós não devemos 
necessariamente considerar um sintoma de perda ou de declínio. Ao invés disso, poderíamos entendê-la como uma realização tardia daquela utopia da liberdade subjetiva diante do legado e das instituições culturais com a qual sonhara Walter Benjamin nos parágrafos derradeiros de seu ensaio sobre "A obra de arte na era da sua reprodutibilidade técnica”. ${ }^{15}$

É claro que não é impossível imaginar um futuro da leitura em que a heterogeneidade do momento que vivemos terá se cristalizado em uma imagem mais coerente daquilo que vem a ser a "cultura da leitura da era eletrônica”. Treze anos após a virada do século XXI, podemos afirmar somente que a situação da leitura nos parece infinitamente complexa, repleta de tensões, mal-entendidos potenciais e fricções produtivas, sem nenhum sinal claro da direção que ela tomará ${ }^{16}$. Meu objetivo foi mostrar o quanto a situação presente da leitura foi influenciada pelas condições institucionais e cronotópicas específicas sob as quais se deu a revolução eletrônica - a qual, desde então, não cessa de nos surpreender.

\footnotetext{
15 Para aspectos críticos de tais visões, ver Hans Ulrich Gumbrecht / Michael Marrinan (eds.): Mapping Benjamin. The Work of Art in the Digital Age. Stanford, 2003.

${ }^{16}$ Essa impressão foi confirmada com um número recente da New Literary History dedicado a novas formas e motivações para a leitura na crítica francesa contemporânea (New Literary History, 44 (2013); de modo que a situação parece ser heterogênea e, portanto, intelectual e existencialmente vibrante.
} 
O futuro da leitura? Recordações e Pensamentos por uma Abordagem Genealógica Autor: Hans Ulrich Gumbrecht

Tradutor: Nelson Shuchmacher Endeb

Revisor: Marcelo de Mello Rangel

Universidade do Estado de Santa Catarina - UDESC

Programa de Pós-Graduação em História - PPGH

Revista Tempo e Argumento Volume 10 - Número 24 - Ano 2018 tempoeargumento@gmail.com 